\title{
Transcription Factor as Therapeutic Targets for Neurodegenerative Disorders: An Update
}

\author{
Rishi Pal* and Prafulla Chandra Tiwari \\ Department of Pharmacology \& Therapeutics, King George's Medical University, India \\ *Corresponding author: Rishi Pal, Department of Pharmacology \& Therapeutics, King George's Medical University, India \\ Submission: 此 February 6, 2018; Published: 㒀 April 02, 2018
}

\begin{abstract}
The neurodegeneration is process of the progressive loss of structure and/or functions including death of neurons. Many neurodegenerative disorders such as amyotrophic lateral sclerosis (ALS), Parkinson's, Alzheimer's, and Huntington's diseases occurred as a result of neurodegenerative processes. These neurodegenerative diseases are constantly on rise worldwide. Various transcription factors involved in the pathogenesis of neuroinflammatory degenerative disorders. The involvement of the latent and active transcription factors are the current focus and target for researchers to work in this area of research. The current review is focused on the regulation of various transcription factors as a therapeutic target for these noncurable diseases.
\end{abstract}

\section{Introduction}

Neurodegeneration is colloquially used for progressive loss of structure or functions of neurons, including death of neurons. Neurons form the core of nervous system which includes brain and spinal cord. Neurons, being terminally differentiated cells can't be replaced by the body when they get damaged or die. Neurodegenerative diseases such as Parkinson's, Alzheimer's and Huntington's diseases are progressive neurodegenerative disorder and have symptomatic cure only which then leads to problems with body movement (ataxia) in Parkinson's disease and cognitive function (dementia) in Alzheimer's disease [1,2]. Transcription factors involved in pathogenesis of neurodegenerative disorders are now explored to develop therapy for these disorders in order to halt progressive loss of neurons [3].

Transcription Factors as Potential Target in Parkinson's Disease

After decades of research on Parkinson's disease, researchers have generated rich and complex knowledge. We now know that dynamic changes in genome is linked with Parkinson's disease, foundation of which was set by discovery of mutations, which promote programmed death of dopaminergic neurons [4-13]. Saha et al. [14], in their study have reported that over-expression of wild type or mutant $\alpha$-synuclein in cultured neurons causes apoptosis and increases sensitivity to apoptotic cell death [14]. Martin et al. [15] and Smith et al. [16] have reported that A53T mutant $\alpha$-synuclein mice have markers of apoptosis in neocortex, brainstem, and spinal cord $[15,16]$. Similarly, mutations in DJ-1 increases oxidative stress induced apoptotic cell death, while pathogenic mutation or knockdown of DJ-1 makes cells hyper sensitive to apoptosis [17-20]. Mutation or depletion of PINK1 sensitizes cells towards apoptotic cell death [21,22].

Dopaminergic neurons have defects in normal regulatory circuit which governs their physiology. There are numerous regulators that are found to govern these neurons. Complexity of these regulators provokes various questions; such as how many regulators must be disrupted for developing Parkinson's disease and which of these regulators are affected by external signals that dopaminergic neurons receive. Can the large variety of genes associated with Parkinson's disease be tied to small regulatory circuits?

It has been suggested by researchers after generating vast knowledge on Parkinsonism that Parkinson's disease is manifestation of alterations in regulation of transcription factor controlling inflammation and survival of neurons. In this review, key transcription factors and their functional importance in the prognosis of PD have been discussed.

\section{NF-KB and Parkinson's Disease}

Inflammatory mediators involved in inflammation and degeneration of dopaminergic neurons and their expression in microglia are regulated by NF- $\kappa$ B. Studies have shown that gene expression of many of proinflammatory responses is controlled by transcription factor NF- $\mathrm{BB}$. Researchers have described NF- $\mathrm{B}$ as a "master switch" for gene expression of various inflammatory mediators [23].

Classical or canonical and the alternate or non-canonical pathways are two major pathways of NF- $\kappa$ B activation. Production of pro-inflammatory mediators is regulated by classical pathway [24]. Classical pathway is mediated through activation of Rel 
protein dimers p50 and p65, complexed with inhibitory $\mathrm{I} \kappa \mathrm{B} \alpha$ in the cytosol. Activation of the classical NF- $\mathrm{B}$ pathway depends on phosphorylation, ubiquitination, and subsequent proteasomal degradation of $I \kappa B \alpha$. I $\kappa$ B kinase (IKK) is a molecular complex of three proteins and consists of heterodimers of IKK $\alpha$ and IKK $\beta$, along

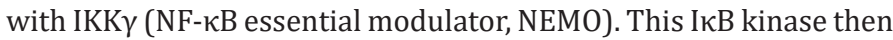
phosphorylates IKB $\alpha$ on serine residue. IKK activation in response to inflammatory mediators such as TNF $\alpha$, IL-1 $\beta$, and LPS depends on IKK $\gamma$ (NEMO) subunit of the IKK complex 88 results in IКB phosphorylation by IKK $\beta$.

Researchers have found that canonical pathway of NF- $\kappa B$ is highly activated during degeneration of dopaminergic neurons in substantia nigra of brains of patients suffering from Parkinson's disease. Thus, constitutive up regulation of canonical pathway of transcription factor NF- $\kappa \mathrm{B}$ in substantia nigra leads to neuronal cell death via apoptotic cell death pathway by Figure 1 [25-27]. Induction of $\mathrm{p} 53$ causes activation of NF- $\mathrm{KB}$ which correlates with the ability of p53 to induce apoptosis. Inhibition or loss of NF- $\kappa B$ activity abrogates p53 induced apoptosis which suggests that NF$\kappa B$ is essential for p53 mediated apoptosis [28]. Classical pathway of NF- $\mathrm{\kappa B}$ also promotes apoptotic proteins such as BCL2, FLIP and Caspases which then take neurons towards programmed cell death.

\section{STAT3 and Parkinson's Disease}

Transient activation of STAT3 promotes inflammation while its prolonged activation has anti-inflammatory effect (Figure 1).

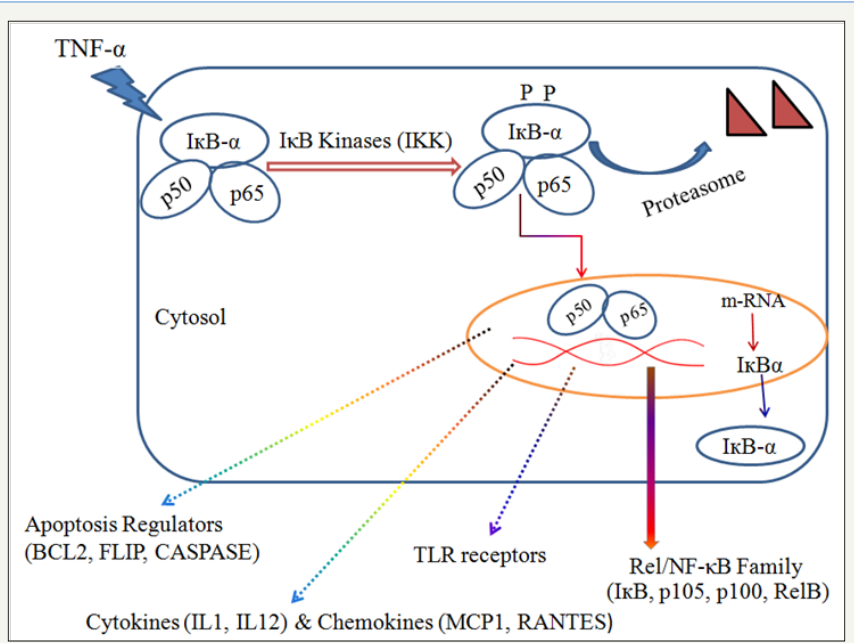

Figure 1: Canonical/Classical Pathway of NF-kB Activation leads towards Apoptotic Cell Death.

Activation of STAT3 in inflamed microglia takes dopaminergic neurons towards programmed cell death or apoptotic pathway through transcriptional activation of cell death mediating genes such as Bcl-xL, caspases, Fas and trail along with genes regulating cell cycle progression, such as p21waf1.Thus, the activation of microglia by STAT 3 causes functional changes such as dopaminergic neuron attenuation in an IL-1-dependent manner as a result of autophagocytosis and results in PD-like behavioural impairment [29-31] (Figure 2).

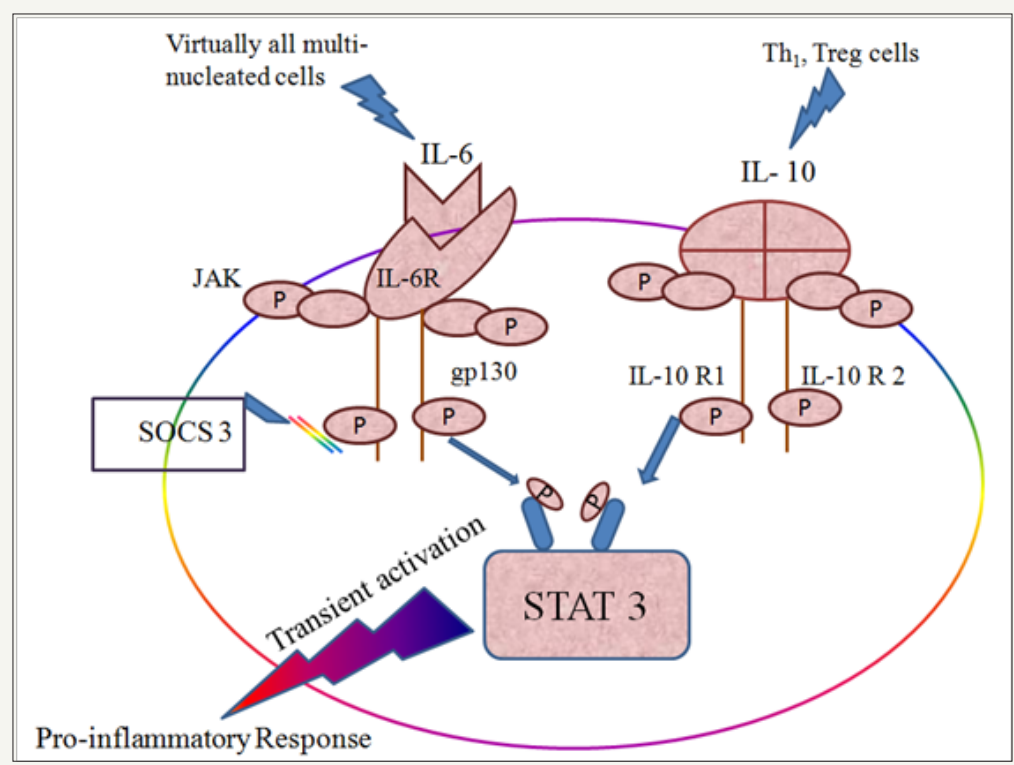

Figure 2: Pro-inflammatory response of Transient activation of STAT 3 pathway. 


\section{TGF- $\beta$ and Parkinson's disease}

TGF- $\beta 1$ is a multifunctional cytokine which regulates growth, differentiation, and functions of immune and nonimmune cells. Researchers have shown that TGF- $\beta 1$ is a potent negative regulator of inflammation $[32,33]$.

TGF- $\beta$ has neuroprotective effect also. It exerts its neuroprotective effect by promoting phosphorylation of Bad, a proapoptotic protein of the Bcl-2 family, through activation of the Erk/ MAP kinase pathway [34]. This neuroprotective effect of TGF- $\beta$ is inhibited in Parkinson's disease by SMAD7, which is activated by either NF- $\mathrm{B}$ pathway or STAT1 pathway in microglia [35].

\section{Transcription Factors as Potential Target in Alzheimer's Disease}

Alzheimer's disease (AD) is a neurodegenerative disorder conjoined with increase in age and is commonest form of dementia in venerable people. Though exact cause of Alzheimer's disease is not yet known, increasing amount of evidences from genetic, pathological, and functional studies suggest that accumulation of amyloid- $\beta(A \beta)$ peptide in the senescent brain $[2,36]$. Aggregation of soluble $A \beta$ oligomers is the precursor to amyloid plaque formation which then set off numerous pathophysiological developments which in due course escort to cognitive dysfunction [37].

$\mathrm{AD}$ is the sixth leading cause of all deaths in developed countries. Number of deaths attributed to $\mathrm{AD}$ has increased drastically in recent years, while other major causes of death are decreasing rapidly. Along with that $\mathrm{AD}$ is one of the costliest disease for the society $[38,39]$. Exact molecular mechanism of AD is not yet fully known, however researchers think that several factors and their interactions are involved in the pathogenesis of PD [40-42]. Therefore, advance research to elucidate mechanism of $\mathrm{AD}$ is of great importance. Researchers have identified several transcription factors such as Stat 1 which are active in AD.

\section{STAT1 and Alzheimer's Disease}

Signal transducer and activator of transcription-1 (STAT1) plays key role in inflammation and the innate immune response; however exact role of STAT 1 in CNS not clearly understood. Researchers have examined the role of STAT1 in spatial learning and memory, and studied its regulation of memory-impairing effect of amyloid-beta $(\mathrm{Ab})[43]$.

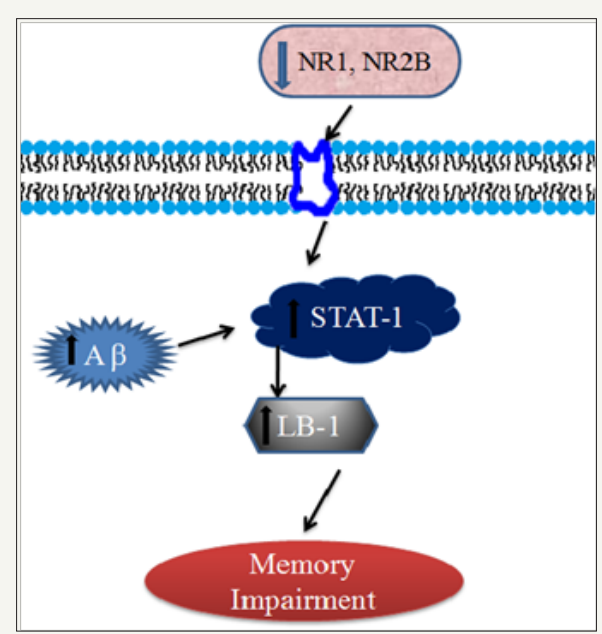

Figure 3: Memory impairment in Alzheimer's disease through STAT 1 pathway.

It has been suggested that increased expression of STAT1 along with Laminin B1 impairs spatial learning and memory induced by $\mathrm{Ab}$ protein which is reversed by complete knockdown of STAT1 (Figure 3). In their 2014 study Hsu WL et al. [43] have shown that spatial learning and memory are negatively regulated by STAT1 through its regulation of LB1 expression. They have also suggested a new mechanism for $\mathrm{Ab}$ pathogenesis which is mediated through STAT1 [43].

\section{NF- $\kappa B$ and Alzheimer's Disease}

NF-кB and Early Alzheimer's Disease: Ab peptide is accumulated intracellular in people vulnerable to Alzheimer's disease such as such as aged people or people exposed to oxidative/ metabolic stressors/toxins/trauma in neural and glial cells. Accumulation of Ab protein is associated with decrease in cognitive abilities.
Increased intracellular $\mathrm{Ca}++$ is observed in neurons having $\mathrm{Ab}$ deposition, which then propels NF- $\kappa \mathrm{B}$ signaling and ensues release of reactive oxygen species (ROS) as well as transactivation of neurotrophins such as nerve growth factor (NGF) and antiapoptotic genes such as Bcl-2 [44].

$\mathrm{Ab}$ peptides stimulate NF- $\mathrm{BB}$ activation in resting microglial cells before plaque formation in neurons. Ab peptides also promote $\mathrm{NF}-\kappa \mathrm{B}$ mediated transactivation of neurotrophic factors such as NGF and brain derived nerve factor (BDNF) and that leads to glial cell activation. These glial cells then secrete TNF- $\alpha$ which expedites ROS inhibition [45-48], thus the collective effect of NF- $\kappa B$ in early AD shifts in favor of neuroprotection.

\section{NF-кB and advanced Alzheimer's disease}

Sustained extracellular accumulation of $\mathrm{Ab}$ peptides and tau 
aggregates increases intracellular $\mathrm{Ca}++$ and leads to activation of $\mathrm{NF}-\kappa \mathrm{B}$. This vivification of NF- $\kappa \mathrm{B}$ then amplifies burden of oxidative stress through release of ROS and release of nitric oxide (NO) by induced nitric oxide synthase (iNOS) in neuronal cells with simultaneous activation of microglial cells [49].

NF- $\kappa \mathrm{B}$ also up-regulates production of excitotoxic glutamate, inflammatory cytokines and oxidative stress in both glial and neural cells which ultimately leads to neuronal damage. Enthused by $\mathrm{Ab}$ deposits, NF- $\kappa \mathrm{B}$ mediated oxidative stress through free radicals and inflammatory cytokines are also up-regulated in adjoining astrocytes. Unrelenting aggregation of deposits leads to a positive feedback loop between activated glia and astrocytes and neuronal cells which ultimately causes synaptic dysfunction, cell death, and persistent $\mathrm{AD}[50,51]$.

\section{Transcription Factors as potential target in Huntington's disease}

Huntington's disease (HD) is a familial neurological disorder of CNS which causes progressive degeneration of striatal cells in the brain [3]. Primarily HD is caused by expansion of codon cytosineadenine-guanine which encodes additional glutamine residues in huntingtin (Htt) protein [52].

\section{NRF-2 Keap 1 and Huntington's disease}

Although, there are several mechanisms through which HD may progress, there is enough credence for the role of oxidative stress in pathogenesis of HD.

Neurons have a significant cellular defense system against oxidative stress induced toxicity in the form of nuclear factor erythroid-2-related factor 2 (Nrf2) signaling path way which is a key signaling pathway in the detoxification of ROS.

In general, Nrf2 is present in the cytoplasm, bound with Kelchlike ECH-associated protein1 (Keap1). During oxidative stress, this Keap1-Nrf2 complex gets distressed and Nrf2 gets segregated from the complex and enters the nucleus and consequently binds to the antioxidant response elements (ARE) of the phase II genes, and increases its rate of transcription as a resistance system against oxidative stress (Figure 4) [53-55].

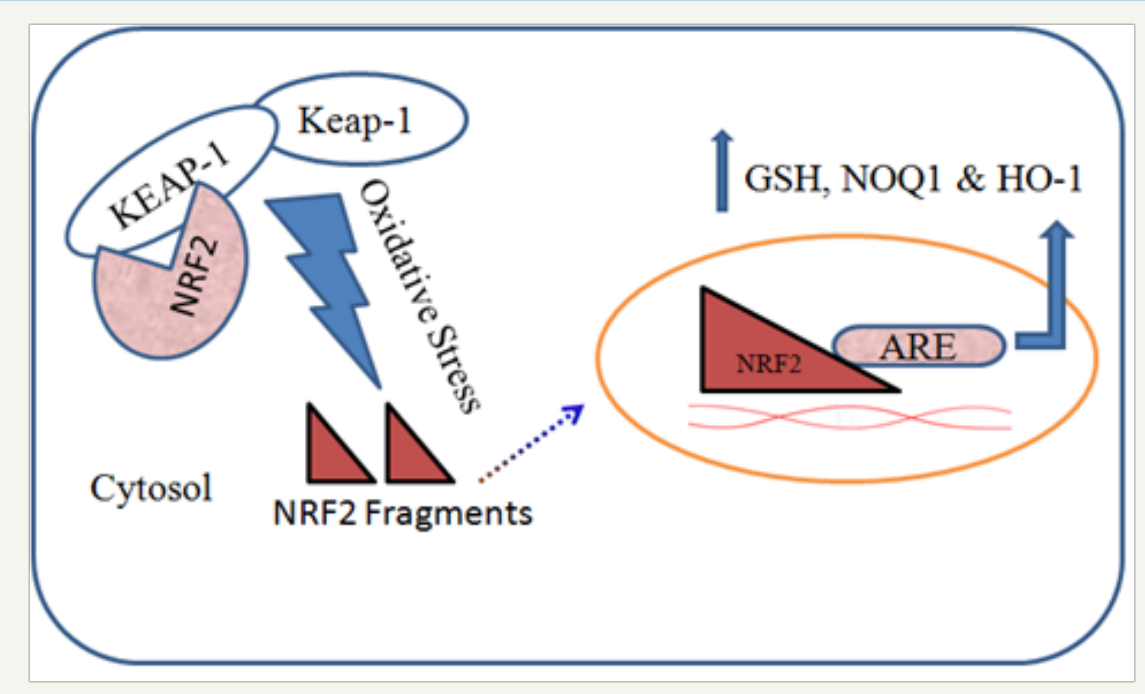

Figure 4: Role of NRF2/KEAP-1 pathway in oxidative stress.

Genes regulated by Nrf2 include phase II detoxification enzymes, along with array of regulators, together with the enzymes NAD(P)H quinone oxidase 1 (NQO1) and heme oxygenase-1 (HO-1). Enzyme NQ01 has neuroprotective effect against oxidative damage by reducing highly reactive quinones to less reactive hydroquinone [56,57].

During the pathogenesis of HD, this pathway is down-regulated, due to which scavenging of free radicals takes a hit and results in increased oxidative stress in neurons. However, exact mechanism of down-regulation of this pathway is yet to be elucidated.

\section{Conclusion and Future Prospects}

The neurodegenerative disorders are constantly on the rise worldwide. Various strategies are planned and focused by the researcher in understanding and management of the neurodegenerative disorders. The pharmacological basis of treatment for such neurological disorders progresses to great extents but permanent cure for these diseases are not much available. The pathological changes and the molecular targets such as involvement of various latent and active transcription factors are the current area of research for such neurodegenerative. So there is need to focus the research on to target transcription factors so that the better understanding of these diseases and their management come to cure neurodegenerative disorders permanently.

\section{References}

1. Pal R, Tiwari PC, Nath R, Pant KK (2016) Role of neuroinflammation and latent transcription factors in pathogenesis of Parkinson's disease. Neurol Res 38(12): 1111-1122.

2. Chen XF, Zhang Yw, Huaxi Xu, Guojun Bu (2013) Transcriptional regulation and its misregulation in Alzheimer's disease. Mol Brain 6(1): 44. 
3. Cho IH (2012) Effects of Panax ginseng in Neurodegenerative Diseases. J Ginseng Res 36(4): 342-353.

4. Tiwari PC, Pal R (2017) The potential role of neuroinflammation and transcription factors in Parkinson disease. Dialogues Clin Neuro ci 19(1): 71-80.

5. Gautam RK (2012) Parkinson's Disease-A Molecular Approach. Journal of Pharmacy Research 5(11).

6. Polymeropoulos MH, Lavedan C, Leroy E, Ide SE, Dehejia A, Dutra A, et al. (1997) Mutation in the alpha-synuclein gene identified in families with Parkinson's disease. Science 276(5321): 2045-2047.

7. Paisan-Ruiz C, Jain S, Evans EW, Gilks WP, Simón J, et al. (2004) Cloning of the gene containing mutations that cause PARK8-linked Parkinson's disease. Neuron 44(4): 595-600.

8. Zimprich A, Bertram Müller-Myhsok, Matthew Farrer, Petra Leitner, Manu Sharma, et al. (2004) The PARK8 locus in autosomal dominant parkinsonism: confirmation of linkage and further delineation of the disease-containing interval. Am J Hum Genet 74(1): 11-19.

9. Bonifati V, Rizzu P, Squitieri F, Krieger E, Vanacore N, (2003) DJ-1( PARK7), a novel gene for autosomal recessive, early onset parkinsonism. Neurol Sci 24(3): 159-160.

10. Schapira AH (2006) Mitochondrial disease. Lancet 368(9529): 70-82.

11. Schapira AH, Cooper JM, Dexter D, ClarkJB, Jenner P (1989) Mitochondrial complex I deficiency in Parkinson's disease. Lancet 1(8649): 1269.

12. Tanner CM (2003) Is the cause of Parkinson's disease environmental or hereditary? Evidence from twin studies. Adv Neurol 91: 133-142.

13. Valente EM, Abou-Sleiman PM, Caputo V, Muqit MM, Harvey K, et al. (2004) Hereditary early-onset Parkinson's disease caused by mutations in PINK1. Science 304(5674): 1158-1160.

14. Saha AR, Ninkina NN, Hanger DP, Anderton BH, Davies AM, et al. (2000) Induction of neuronal death by alpha-synuclein. Eur J Neurosci 12(8): 3073-3077.

15. Martin LJ, Pan Y, Price AC, Sterling W, Copeland NG, et al. (2006) Parkinson's disease alpha-synuclein transgenic mice develop neuronal mitochondrial degeneration and cell death. J Neurosci 26(1): 41-50.

16. Smith WW, Liu Z, Liang Y, Masuda N, Swing DA, Jenkins NA, et al. (2010) Synphilin-1 attenuates neuronal degeneration in the A53T alphasynuclein transgenic mouse model. Hum Mol Genet 19(11): 2087-2098.

17. Martinat C, Shendelman S, Jonason A, Leete T, Beal MF, et al. (2004) Sensitivity to oxidative stress in DJ-1-deficient dopamine neurons: an ES- derived cell model of primary Parkinsonism. PLoS Biol 2(11): e327.

18. Kim RH, Smith PD, Aleyasin H, Hayley S, Mount MP, et al. (2005) Hypersensitivity of DJ-1-deficient mice to 1-methyl-4-phenyl-1,2,3,6tetrahydropyrindine (MPTP) and oxidative stress. Proc Natl Acad Sci 102(14): 5215-5220.

19. Shinbo Y, Niki T, Taira T, Ooe H, Takahashi-Niki K, et al. (2006) Proper SUMO-1 conjugation is essential to DJ-1 to exert its full activities. Cell Death Differ 13(1): 96-108.

20. Yokota T, Sugawara K, Ito K, Takahashi R, Ariga H, et al. (2003) Down regulation of DJ-1 enhances cell death by oxidative stress, ER stress, and proteasome inhibition. Biochem Biophys Res Commun 312(4): 13421348.

21. Mei Y, Zhang Y, Yamamoto K, Xie W, Mak TW, et al. (2009) FOXO3adependent regulation of Pink1 (Park6) mediates survival signaling in response to cytokine deprivation. Proc Natl Acad Sci U S A 106(13): 5153-5158.

22. Wang HL, Chou AH, Wu AS, Chen SY, Weng YH, et al. (2011) PARK6 PINK1 mutants are defective in maintaining mitochondrial membrane potentia and inhibiting ROS formation of substantia nigra dopaminergic neurons. Biochim Biophys Acta 1812(6): 674-684.

23. Tsoulfas G, DA Geller (2001) NF-kappaB in transplantation: friend or foe? Transpl Infect Dis 3(4): 212-219.

24. Hunot S, Bernard Brugg, Damien Ricard, Patrick P. Michel, Marie-Paule Muriel, et al. (1997) Nuclear translocation of NF-kappaB is increased in dopaminergic neurons of patients with parkinson disease. Proc Natl Acad Sci 94(14): 7531-7536.

25. Ohkawa H, Ohishi N, Yagi K (1979) Assay for lipid peroxides in animal tissues by thiobarbituric acid reaction. Anal Biochem 95(2): 351-358.

26. Ryan KM, Ernst MK, Rice NR, Vousden KH (2000) Role of NF-kappaB in p53-mediated programmed cell death. Nature 404(6780): 892-897.

27. Mogi M, Kondo T, Mizuno Y, Nagatsu T (2007) p53 protein, interferongamma, and NF-kappaB levels are elevated in the parkinsonian brain. Neurosci Lett 414(1): 94-97.

28. Ryan KM, Ernst MK, Rice NR, Vousden KH (2000) Role of NF- $\kappa$ B in p53mediated programmed cell death. Nature 404(6780): 892-897.

29. Przanowski P, Dabrowski M, Ellert-Miklaszewska A, Kloss M Mieczkowski J, et al. (2014) The signal transducers Stat1 and Stat3 and their novel target Jmjd3 drive the expression of inflammatory genes in microglia. J Mol Med (Berl) 92(3): 239-254

30. Peterson PK, Hu S, Salak-Johnson J, Molitor TW, Chao CC (1997) Differential production of and migratory response to beta chemokines by human microglia and astrocytes. J Infect Dis 175(2): 478-481.

31. Tanaka S, Ishii A, Ohtaki H, Shioda S, Yoshida T, et al. (2013) Activation of microglia induces symptoms of Parkinson's disease in wild-type, but not in IL-1 knockout mice. J Neuroinflammation 10: 143.

32. Wahl SM (1994) Transforming growth factor beta: the good, the bad, and the ugly. J Exp Med 180(5): 1587-1590.

33. Letterio JJ, Roberts AB (1998) Regulation of immune responses by TGFbeta. Annu Rev Immunol 16: 137-161.

34. Zhu Y, Yang GY, Ahlemeyer B, Pang L, Che XM (2002) Transforming growth factor-beta 1 increases bad phosphorylation and protects neurons against damage. J Neurosci 22(10): 3898-3909.

35. Unsicker K, Krieglstein K (2002) TGF-betas and their roles in the regulation of neuron survival. Adv Exp Med Biol 513: 353-374.

36. Blennow K, de Leon MJ, Zetterberg H (2006) Alzheimer's disease. Lancet 368(9533): 387-403

37. Alzheimer's A (2013) 2013 Alzheimer's disease facts and figures. Alzheimers Dement 9(2): 208-245.

38. Holt J, Stiltner L, Wallace R, Raetz J (2009) Clinical inquiries. Do patients at high risk of Alzheimer's disease benefit from early treatment? J Fam Pract 58(6): 320-322.

39. Alzheimer's A (2011) 2011 Alzheimer's disease facts and figures. Alzheimers Dement 7(2): 208-244.

40. Ikonen M, Liu B, Hashimoto Y, Ma L, Lee KW, et al. (2003) Interaction between the Alzheimer's survival peptide humanin and insulin-like growth factor-binding protein 3 regulates cell survival and apoptosis. Proc Natl Acad Sci 100(22): 13042-13047.

41. Manczak M, Reddy PH (2013) Abnormal interaction of oligomeric amyloid-beta with phosphorylated tau: implications to synaptic dysfunction and neuronal damage. J Alzheimers Dis 36(2): 285-295.

42. Lahiri DK, Sambamurti K, Bennett DA (2004) Apolipoprotein gene and its interaction with the environmentally driven risk factors: molecular, genetic and epidemiological studies of Alzheimer's disease. Neurobiol Aging 25(5): 651-660. 
43. Hsu WL, Ma YL, Hsieh DY, Liu YC, Lee EH (2014) STAT1 negatively regulates spatial memory formation and mediates the memoryimpairing effect of Abeta. Neuropsychopharmacology 39(3): 746-758.

44. Qin ZH, Tao LY, Chen X (2007) Dual roles of NF-kappaB in cell survival and implications of NF-kappaB inhibitors in neuroprotective therapy. Acta Pharmacol Sin 28(12): 1859-1872.

45. Schaeffer V, Meyer L, Patte-Mensah C, Eckert A, Mensah-Nyagan AG (2008) Dose-dependent and sequence-sensitive effects of amyloidbeta peptide on neurosteroidogenesis in human neuroblastoma cells. Neurochem Int 52(6): 948-955.

46. Valerio A, Boroni F, Benarese M, Sarnico I, Ghisi V, et al. (2006) NFkappaB pathway: a target for preventing beta-amyloid (Abeta)-induced neuronal damage and Abeta42 production. Eur J Neurosci 23(7): 17111720.

47. Buggia-Prevot V, Sevalle J, Rossner S, Checler F (2008) NFkappaBdependent control of BACE1 promoter transactivation by Abeta42. J Biol Chem 283(15): 10037-10047.

48. Emmanouil M, Taoufik E, Tseveleki V, Vamvakas SS, Probert L (2011) A role for neuronal NF-kappaB in suppressing neuroinflammation and promoting neuroprotection in the CNS. Adv Exp Med Biol 691: 575-581.

49. Sierra A, Abiega O, Shahraz A, Neumann H (2013) Janus-faced microglia: beneficial and detrimental consequences of microglial phagocytosis. Front Cell Neurosci 7: 6 .

50. Ahmed T, Gilani AH (2011) A comparative study of curcuminoids to measure their effect on inflammatory and apoptotic gene expression in an Abeta plus ibotenic acid-infused rat model of Alzheimer's disease. Brain Res 1400: 1-18.

51. Bales KR, Du Y, Dodel RC, Yan GM, Hamilton-Byrd E, et al. (1998) The NFkappaB/Rel family of proteins mediates A beta-induced neurotoxicity and glial activation. Brain Res Mol Brain Res 57(1): 63-72.

52. Zhang M, An C, Gao Y, Leak RK, Chen J, et al. (2013) Emerging roles of Nrf2 and phase II antioxidant enzymes in neuroprotection. Prog Neurobiol 100: 30-47.

53. Joshi G, Johnson JA (2012) The Nrf2-ARE pathway: a valuable therapeutic target for the treatment of neurodegenerative diseases. Recent Pat CNS Drug Discov 7(3): 218-229.

54. Lyakhovich VV, Vavilin VA, Zenkov NK, Menshchikova EB (2006) Active defense under oxidative stress. The antioxidant responsive element. Biochemistry (Mosc) 71(9): 962-974

55. Patten DA, Germain M, Kelly MA, Slack RS (2010) Reactive oxygen species: stuck in the middle of neurodegeneration. J Alzheimers Dis 20 Suppl 2: S357-67.

56. Sykiotis GP, Habeos IG, Samuelson AV, Bohmann D (2011) The role of the antioxidant and longevity-promoting Nrf2 pathway in metabolic regulation. Curr Opin Clin Nutr Metab Care 14(1): 41-48.

57. Lee JM, Calkins MJ, Chan K, Kan YW, Johnson JA (2003) Identification of the NF-E2-related factor-2-dependent genes conferring protection against oxidative stress in primary cortical astrocytes using oligonucleotide microarray analysis. J Biol Chem 278(14): 12029-12038.
Creative Commons Attribution 4.0 International License

For possible submissions Click Here

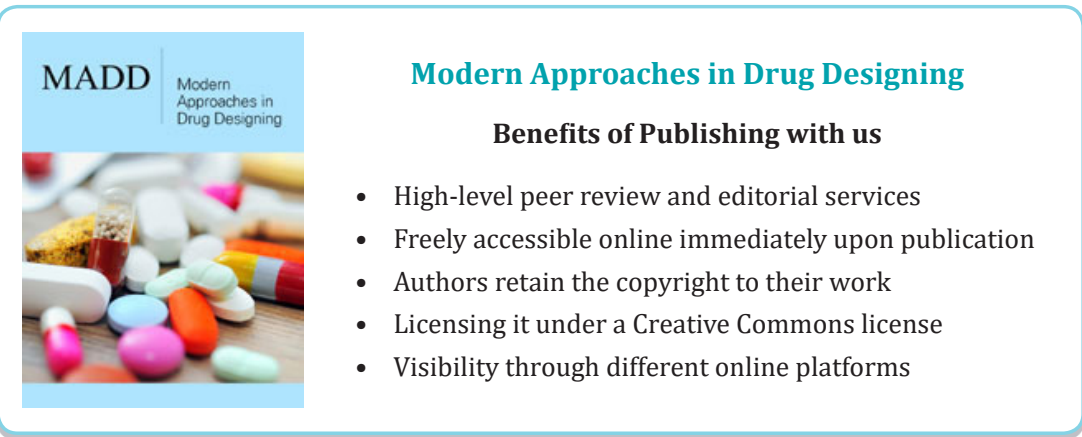

